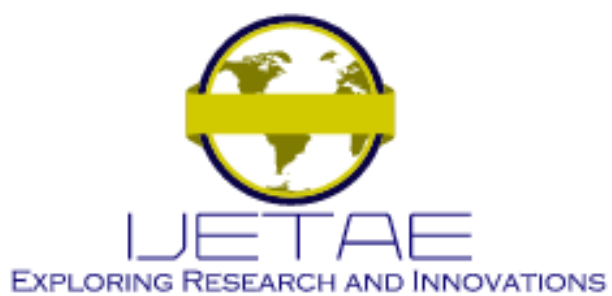

International Journal of Emerging Technology and Advanced Engineering

Website: www.ijetae.com (E-ISSN 2250-2459, Scopus Indexed, ISO 9001:2008 Certified Journal, Volume 12, Issue 01, January 2022)

Manuscript Received: 02 December 2021, Received in Revised form: 04 January 2022, Accepted: 10 January 2022

DOI: 10.46338/ijetae0122_06

\title{
Design Radio Network Links to Provide Internet for Pupulation of San Andres de Llamellin-Ancash
}

\author{
Andres Valencia-Acuña ${ }^{1}$, Brian Meneses-Claudio ${ }^{2}$, Alexi Delgado ${ }^{3}$ \\ ${ }^{1,2}$ Universidad de Ciencias y Humanidades \& Av. Universitaria 5175, Los Olivos 15304 \\ ${ }^{3}$ Pontificia Universidad Católica del Perú \& Av. Universitaria 1801, San Miguel 15088
}

\begin{abstract}
In recent years being able to have access to the internet has become a tool not only to be able to communicate in the distance but it is a great tool to be able to feed knowledge, it is because of them that children have a great educational utility and after this pandemic in Peru it was necessary to close schools, to be able to give remote classes or virtual classes. To solve the problem, we propose to be able to design a network of radio links whereby means of a base station of emission and reception, with an antenna of sectorial type and directional antennas to be able to realize a Point Multipoint link which will be able to manage the quality of signal by means of a routing with functions of control of speeds for each connection of each home. It was the result that the connections of the radio link at an average distance from the coverage that the network had the signal was better and that the connections that were very far or close to the coverage area had complications, but despite this the connections were sufficient to be able to maintain the virtual classes that is what was planned. It is recommended that for a better connection and complete coverage it would be to reinforce the broadcast base with more sectoral antennas in the network.
\end{abstract}

Keywords-- Radio link, Point - Multipoint, Router, Download speed, Upload speed.

\section{INTRODUCTION}

In this era of modernity, not being connected to the internet has become a problem that roots that students have a limitation before their educational development; in this pandemic that great problem was amplified; according to [1] IBRD-IDA (International Bank for Reconstruction Development - International Development Association), the percentage in the world of people who use the internet is only $49 \%$ so much of the world is totally isolated from the internet and the educational benefitsitprovides, already in [2] Ecuador gave a solution to be able to give access to the parishes where several populations far from the capital or distant towns were educated.
Education in Peru before the pandemic according to [3], [4] INEI (National Institute of Statistics and Informatics) indicates that $81.4 \%$ of children from 3 to 5 and $92 \%$ of children from 6 to 11 years attended classes; but it has changed suddenly before this new form of education at home where in [5] INEI indicates that only $38 \%$ have access to the internet at home and according to [6] only $35.4 \%$ have a computer in their homes so having an adequate education in this confinement is something very disadvantageous for remote sectors.

In the department of Ancash the lack of internet connection has been a big problem in this pandemic; in [5] and [3] INEI indicates that $32.4 \%$ have internet at home; this leaves $93 \%$ of students who attended face-to-face classes today cannot have that education because in [6]only30.3\% of households have a computer; the lack of being able to carry out a good education has become a problem, more for remote villages and because of their geography it is difficult to access; before this problematic radio link solutions in [7] where there are cases in Huancayo in the Urbanization of Palian using PPDIOO (Prepare, Raise, Design, Implement, Operate and Optimize). Vila Gamarra, Anderson (2020) Deployments of a wireless network based on the PPDIOO methodology for the improvement of internet service in the urbanization of Palian.

In the present work it is aimed to carry out the design of a radio as in [9] Point-Point and Point-Multipoint link to then be able to manage the network created giving internet access to the population of San Andres de Llamellin Ancash - Peru; with a purely educational approach to be able to provide them with that tool so that they can access an education through the connections that will bring internet access to each home in this' populated with the restrictions of only being able to enter purely educational sites. 


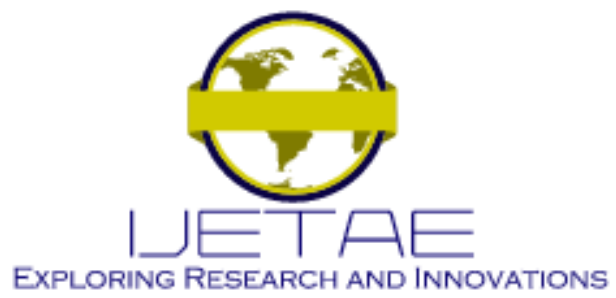

International Journal of Emerging Technology and Advanced Engineering

Website: www.ijetae.com (E-ISSN 2250-2459, Scopus Indexed, ISO 9001:2008 Certified Journal, Volume 12, Issue 01, January 2022)

\section{LITERATURE REVIEW}

In , they identify that in the villages far from the capitals there is a lack of connectivity to the basic needs of the internet and this is corroborated by seeing in the INEC (National Institute of Statistics and Census) the percentages are low in households with Internet in distant towns so seeing that the wire connection is limited by the geography of the areas is why they propose in this descriptive research to take data to be able to determine that the wireless solution is the best for this rural Parish of San Luis de Pambil, so they decided to form an experimental link that was analyzed by means of a software the distance of $26 \mathrm{~km}$ that was needed to be able to make a point-to-point link and should be made of a tower of 18 meters from the Quevedo Canton where there is a connection point; to have the optimal link you need at least a gain of $-60 \mathrm{dBm}$ to guarantee the quality of the link; to then be able to conduct a survey of a sector of the population so that your sample would be 355 as presented to see if the objectives presented are valid or invalid. As a result he told us that of the 355 people only $12 \%$ have internet and $88 \%$ do not, and of the households without internet $77 \%$ if they would hire a service while $23 \%$ would not hire it, with the software it was verified that in a link of $5.8 \mathrm{GHz}$ a gain of $-52 \mathrm{dBm}$ would be achieved and so it is concluded that in the research they carried out they give an alternative for the inhabitants who do not they have internet because of how economical it would be not only in the infrastructure but in the user, so they give as a large market since the amount of population without this service is too much.

In [8] they identified a problem with network connections in the study center Ocho De Enero Del Canton of Ecuador; even more so because of the increase in students, so to improve this problem it is proposed to be able to provide a better connection and redistribution of the internet signal to the Institute; using UBIQUITI brand equipment to be able to better manage each equipment and optimize its functions for what they first did a survey to the entire population of the Educational Institution from the students and teachers to the administrative staff to know the problems that have occurred in the current internet connections; in order to subsequently proceed according to the data to proceed to select the equipment to be supplied which according to characteristics that fit the needs to improve the problem of internet connection; for a better connection to both laptop and Tablet of the Institution so as a next step the equipment is installed starting with the base of the network that is the positioning of the router that is configured to be able to assemble the wireless network and physical connections with certain restrictions that are needed according to the aria of the Educational Institution for what part of the configuration would be the creation of IP addresses, captive portal, control of upload and download speeds and finally block access to different websites; for the next step that would be to be able to see the results that are given is compared with the above, that before only $25 \%$ was used and the rest is wasted, now the percentage is $90 \%$ and obtaining improvements and restrictions from different websites, less the educational ones to which students can have access and teachers to more beneficial subjects for the realization of their classes. As a conclusion, it is indicated that the equipment was installed according to the specifications resulting in the total coverage of the institution and an adequate speed for the students and the segmentation of the arias of the Educational Institution, thanks to the specifications of equipment of the brand used.

In [7] we see that in the thesis they see the problem in the Urbanization of Palian of the poor quality of a wired internet service that provides only a maximum of $2 \mathrm{Mbps}$ and only guarantees $10 \%$ of it, so it was proposed the creation of a wireless network based on the PPDIOO methodology for which preparation is carried out first where the business model that will make known to how many users will be directed, the bandwidth to use and the selection of the technology that would be needed to be able to perform antennas, routers and switches. Second Planning where the analysis and requirements for the network to be implemented as the map of the urbanization is carried out to be able to analyze the objectives that are to improve the quality of the internet for which the technical analysis will be given in scalability, availability, performance, security and then go to the work plan where it will indicate in what time the PPDIOO will be carried out. Third Design of the network where the physical and logical design of the network would be carried out through graphics. Fourth Implementation of the network that is first based on the configuration of the core creating the base that would be the main routers that would create the network and manage the entire network and creating the structure and IP addresses to then assign the other equipment the IPs and configure the antennas and routers and control the bandwidth that was determined for each user. Fifth Operation of the network is the one that will be given the monitoring and control that allows to verify the quality that is being granted to the users and verify if it is what is planned, such as the bandwidth, levels of connectivity for the users. 


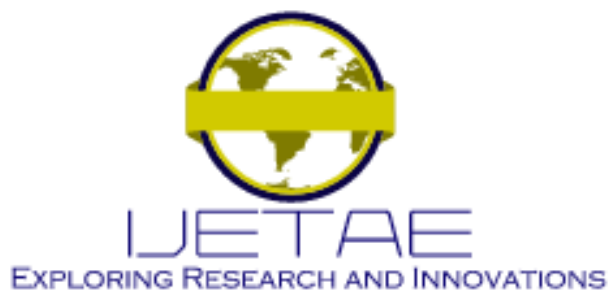

International Journal of Emerging Technology and Advanced Engineering Website: www.ijetae.com (E-ISSN 2250-2459, Scopus Indexed, ISO 9001:2008 Certified Journal, Volume 12, Issue 01, January 2022)

Sixth Optimization of the network that will be verified by logical ports and give a software update to the equipment according to the progress of each equipment for the best performance over time of the equipment. The results obtained that the downloads reached about $4 \mathrm{Mbps}$ and uploaded in $1.7 \mathrm{Mbps}$ in the end users, the implemented network had not only improvements in broadband but is uploads and downloads and response times to connection problems. As a result, a more economical wireless network is made; the improvement in speed, increase in download and the improvement of internet quality in the urbanization of Palian. In conclusion, using the PPDIOO methodology provides not only a better structure, planning and design that makes a wireless network project more economical and efficient.

\section{TECHNOLOGY}

A point-multipoint system (PTMP) is a term used in telecommunications; is defined as the communication of a specific point to different points; from one point offers several routes; an antenna that manages to receive multiple connections using multiplexing by division in time to be able to make communication that allows a better communication between them, these routes or routes are made through wireless connections in Gigahertz frequencies. A point-to-point system (PTPT) is a directional communication where there is a single sender and receiver, where wireless signals are used as a medium at frequencies equal to those of a multipoint point connection that are from $900 \mathrm{MHz}$ to $2.4 \mathrm{GHz}$ and in the frequency from $5.1 \mathrm{GHz}$ to $5.8 \mathrm{GHz}$; the distances that can be covered in both PTPT and PTMP systems depends on their power and their gain that they have. In [10] the Routers are used to be able to receive and send data from computer networks which allows us to be able to carry out the communication and have a computer that can manage the networks and this can be scaled according to the type of network that is handled is WAN OR LAN, this equipment one of its utilities is to be able to distribute the IP addresses to recognize the different types of equipment in a communication network wired or wireless.

Wireless technologies such as MU-MIMO ensure that not only communication is one by one but now allows us to have multiple communications simultaneously; as another great advance to be able to make connections in a frequency of $5.8 \mathrm{GHz}$ is of great help to have greater bandwidth and that compared to the frequency $2.4 \mathrm{GHz}$ which is a frequency that is saturated.
This research work has a structure consisting of the following way, section II describes the methods and design of a radio link. In section III the results obtained from the radio link are announced, and then in section IV to discuss the methodology and results; finally, in section $\mathrm{V}$ we will present our conclusions as recommendations for possible similar work.

\section{METHODOLOGY}

In the present work was carried out to be able to grant internet to the homes of the students of the town of San Andres de Llamellin, who lack this service, it is a proposal that aims to give a tool for the improvement of their education.

In this figure we can see the flowchart of the research work.

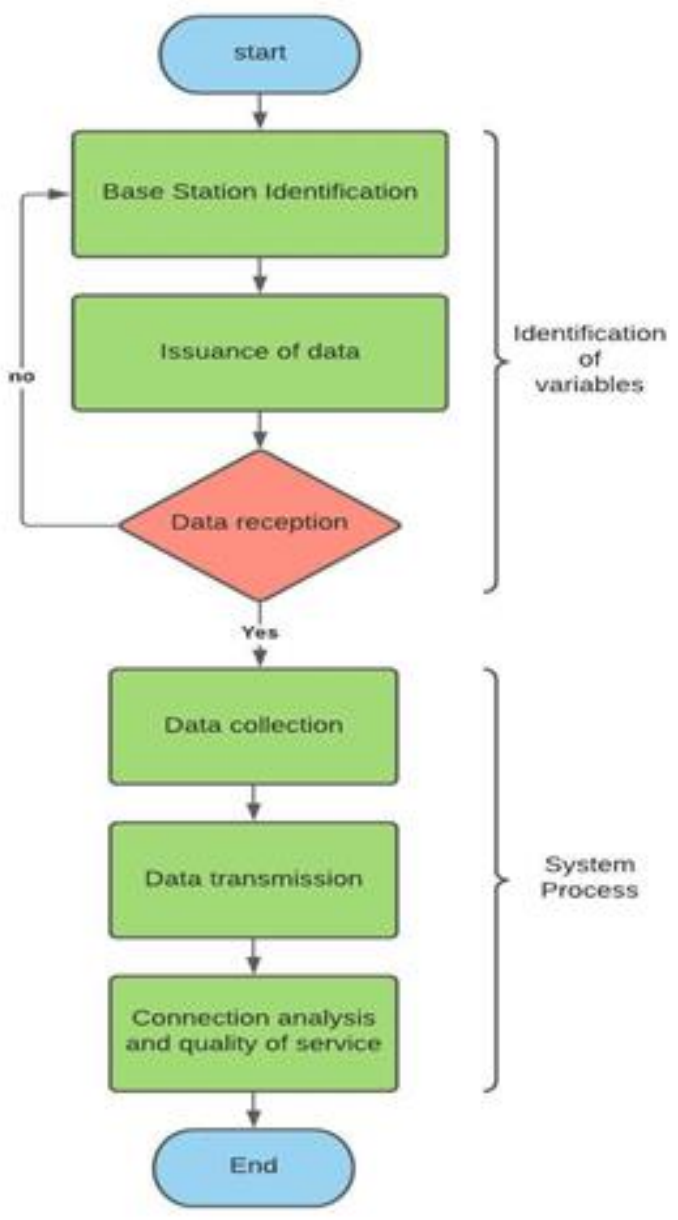

Fig. 1. Flowchart 


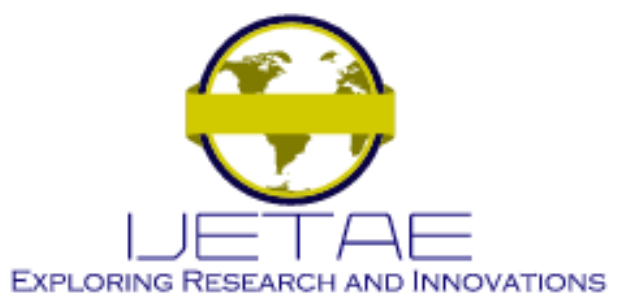

International Journal of Emerging Technology and Advanced Engineering Website: www.ijetae.com (E-ISSN 2250-2459, Scopus Indexed, ISO 9001:2008 Certified Journal, Volume 12, Issue 01, January 2022)

\section{A. Identification of Variable}

For this part we will present the characteristics of the antennas that we will use in the project.

LBE-5AC-GEN2 directional antenna which is used to perform point-to-point radio links or as receivers of a multipoint point; in [11] this antenna works on the frequency of $5.8 \mathrm{GHz}$, works with an interface up to $1 \mathrm{Gbps}$ and with a capacity of antler about 1 kilometers in the field, they are a great equipment that are used for wireless signals for the bandwidth they can receive. Such characteristics will be shown in Table 1.

TABLE 1:

Characteristics OF THE Directional ANTENNa

\begin{tabular}{|l|l|}
\hline MODEL & LBE-5AC-GEN2 \\
\hline ANTENNA GAIN & $23 \mathrm{dBi}$ \\
\hline MAXIMUM OUTPUT POWER & $25 \mathrm{dBm}$ \\
\hline FEEDING METHOD & Passive SOP \\
\hline MAXIMUM ENERGY CONSUMPTION & $7 \mathrm{~W}$ \\
\hline WORKING FREQUENCY & $5 \mathrm{GHz}$ \\
\hline SERTIFICATION & FCC and ISED \\
\hline
\end{tabular}

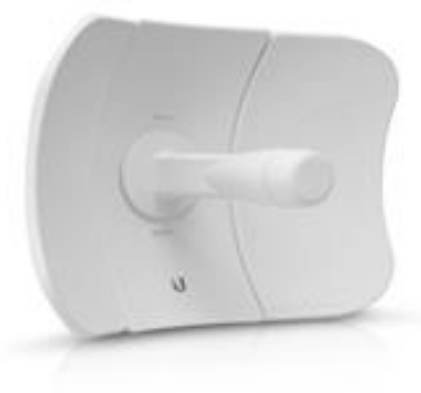

Fig. 2. LBE-5AC-GEN2

In [12] TheAM-5G19-120 antenna s antenna that is used for multipoint point radio links as the base antenna since it has the advantage that the radius it covers is up to about $5 \mathrm{~km}$ and $120^{\circ}$ of amplitude, so it allows that in wireless networks to cover a range where it can have communication with several receiving antennas, we will see in Table 2.
TABLE 2:

Characteristics of THe Sectoral ANTEnNa

\begin{tabular}{|l|l|}
\hline MODEL & AM-5G19-120 \\
\hline WORKING FREQUENCY & $5.15-5.85 \mathrm{GHz}$ \\
\hline GAIN & $18.6-19.1 \mathrm{dBi}$ \\
\hline HPOL AMPLITUDE & $123^{\circ}(6 \mathrm{~dB})$ \\
\hline VPOL AMPLITUDE & $123^{\circ}(6 \mathrm{~dB})$ \\
\hline LINEEAL POLARIZATION & DOUBLE \\
\hline CROSS POLARITY ISOLATION MIN. & $28 \mathrm{dBm}$ \\
\hline
\end{tabular}

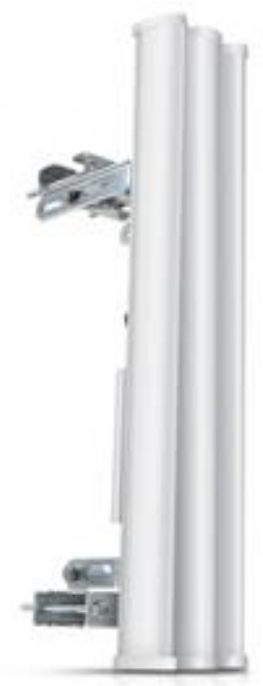

Fig. 3. AM-5G19-120

In the beginning for a radio link base it is essential so that the ROCKET M5 model will be used that will be responsible for being able to give the power to the sectoral antenna to be able to reach the other antennas, which must work at the same frequency of the other antennas to work to be able to make a communication so in [13] that ROCKET M5 model works on the $5 \mathrm{GHz}$; these specifications and more we will see in Table 3. 


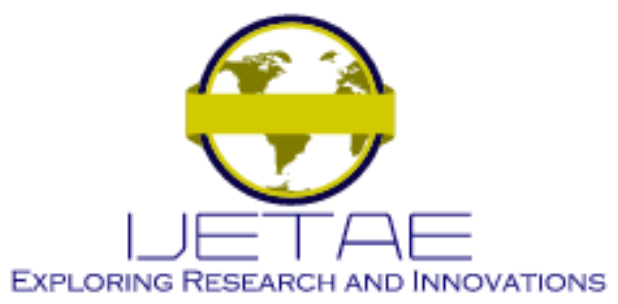

International Journal of Emerging Technology and Advanced Engineering

Website: www.ijetae.com (E-ISSN 2250-2459, Scopus Indexed, ISO 9001:2008 Certified Journal, Volume 12, Issue 01, January 2022)

TABLE 3:

Characteristics of THE SECTORAL ANTENNa BaSE

\begin{tabular}{|l|l|}
\hline MODEL & ROCKET M5 \\
\hline HIGH POWER & $2 \times 2$ MIMO \\
\hline FEED & POE \\
\hline SECTOR COMPATIBLE & AM-5G19-120 \\
\hline BRIDGE AND APPLICATIONS IN & BASE STATION \\
\hline
\end{tabular}

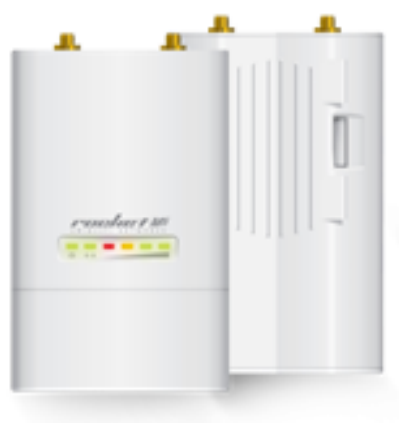

Fig. 4. ROCKET M5

Router to be used will be two models for each area to need that would be the base station RB750GR3 and for homes to receive the signal to be able to distribute the TLWR850N model. For each area the characteristics are different in scales since the functionality would be the same because the equipment of the base station is a more manageable equipment than the basic equipment for the final recipient.

In [14] Router RB750GR3 is a manageable model of the MIKROTIK brand; it will help us to be able to give static IPs for each computer in our network and to be able to block the equipment that is not in the IP list and some pages that would not help us for this purpose that is a more educational internet, and to be able to regulate both uploads and downloads to the network. We will see this in Table 4.
TABLE 4:

FEATURES OF THE MANAGEABLE ROUTER

\begin{tabular}{|l|l|}
\hline MODEL & RB750GR3 \\
\hline SPEED OF NETWORK PORTS & $1 \mathrm{Gbps}$ \\
\hline ROUTER OS LICENSE & 4 \\
\hline RAM & $256 \mathrm{MB}$ \\
\hline STORAGE SIZE & $16 \mathrm{MB}$ \\
\hline STORAGE TYPE & FLASH \\
\hline MAXIMUM ENERGY CONSUMPTION & $10 \mathrm{~W}$ \\
\hline
\end{tabular}

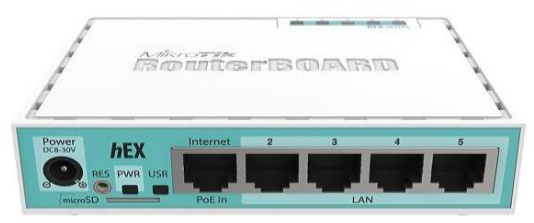

Fig. 5. RB750Gr3

In [15] Router TL-WR850N is a router for customers or home users, so easy to configure for a radio link network that will be responsible for being able to distribute internet for end users, these characteristics will be reflected in Table 5 that we will see.

TABLE 5:

Characteristics OF THE Client Router.

\begin{tabular}{|l|l|}
\hline MODEL & TL-WR850N \\
\hline BANDWIDTH & $300 \mathrm{Mbps}$ \\
\hline WAN PORT TYPE & $\begin{array}{l}\text { Dynamic } \\
\text { IP/Static } \\
\text { IP/PPPoE/ } \\
\text { PPTP/L2TP }\end{array}$ \\
\hline PROTOCOLS & IPv4 and IPv6 \\
\hline 5-PORT SPEED & $10 / 100$ Mbps \\
\hline FACTORY & YES \\
MODIFICATION & 9VDC/0.6A \\
\hline EXTERNAL POWER SUPPLY &
\end{tabular}




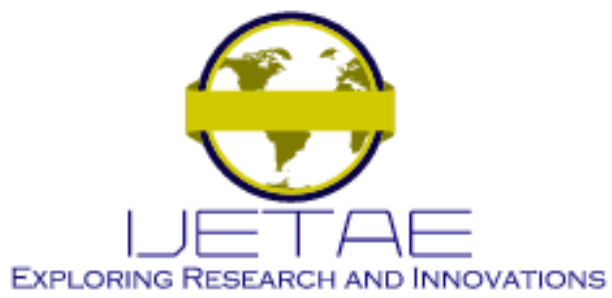

International Journal of Emerging Technology and Advanced Engineering

Website: www.ijetae.com (E-ISSN 2250-2459, Scopus Indexed, ISO 9001:2008 Certified Journal, Volume 12, Issue 01, January 2022)

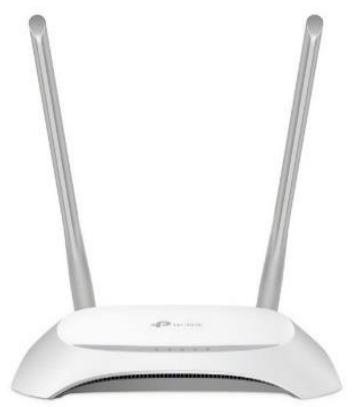

Fig. 6. Figure 5. TL-WR850N

\section{B. System Process}

In the first stay you will start with the connections of the base antenna placing as the brain, or administrator to the Router RB750Gr3 that will be connected to its external source and the modem of the internet provider, for which a bridge is plowed so that our router obtains control of the bandwidth that you give us to be able to supply it in the best way in the population, which will be seen in the image below

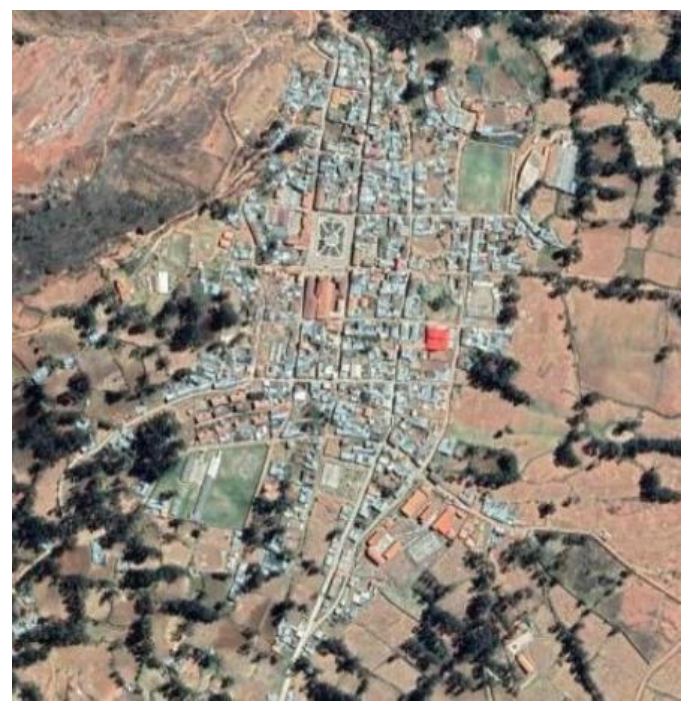

Fig. 7. San Andres de Llamellin
To then be able to make the connection by ethernet cable of the router to the POE device (Power over Ethernet) of the same equipment that will be connected to both the power for the equipment and the ethernet network point; which will be joined to by a single ethernet cable carry data and energy for the Rocket M5 that will use the AM-5G19120 sector antenna that will be connected by its pole connections and be able to lift these equipment for its operation.
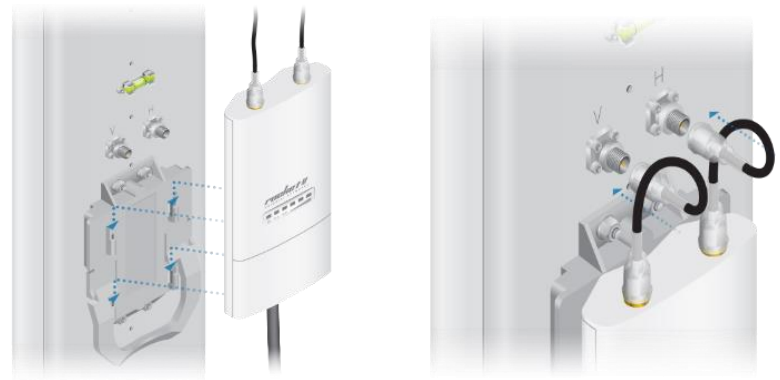

Fig. 8. Connection in the antenna

For the connections of the stations, they must be in the $120^{\circ}$ range of the base station; these multipoint stations will be connected by the LBE-5AC-GEN2 antenna that will be seen in the following image.

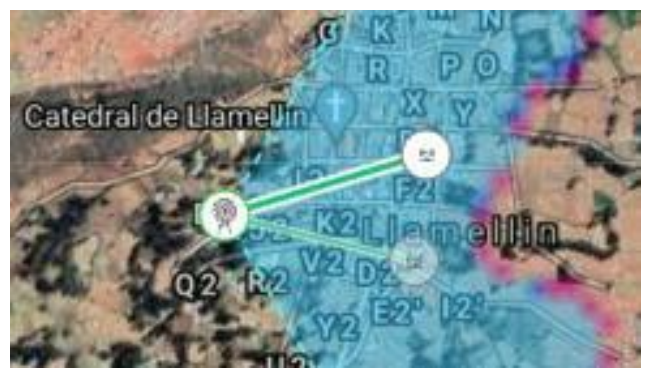

Fig. 9. Antenna position

The antennas will be connected to a router through a POE connection that will allow the antenna to reach the connection to the router and be able to be energized, so that the TL-WR850N router can be powered by an external source; for the operation of the equipment to be able to distribute the bandwidth that will receive from the central base of the radio link network. 


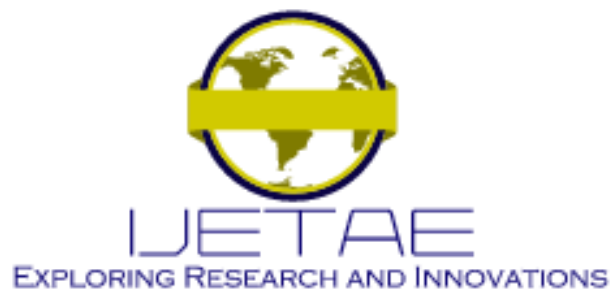

International Journal of Emerging Technology and Advanced Engineering Website: www.ijetae.com (E-ISSN 2250-2459, Scopus Indexed, ISO 9001:2008 Certified Journal, Volume 12, Issue 01, January 2022)

The radius link that we created will maintain a maximum distance of $625 \mathrm{~m}$ and a min distance of $260 \mathrm{~m}$ so in the connections it was averaged that distances would be handled as in this image.

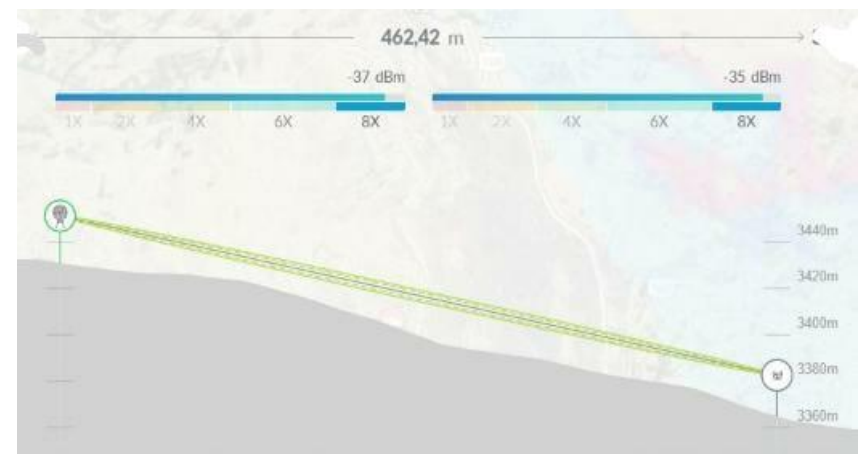

Fig. 10. Figure 8. Average distance from the radio link

Configuration of the radio link system.

To begin with the configuration of this radio link will first proceed to configure the transmission base that will consist of the ROCKET M5, for which accessing the configuration portal through a laptop in a buscador proceeds to place the IP that has by default that is ña 192.168.1.20, which allows us to access the equipment once entered the first thing is to be able to change the username and password of access of the equipment; then you must proceed to the placement of the IP in the range that would be worked, for which it is suggested that the range of masks 255.255.255.0 ; step followed will go to the WIRELES section to be able to place the configuration modem that will have the equipment that will be Access Point for what will use the AM-5G19-120 antenna to be able to send the Wireless signal to each client station, will also put the channel with which to work that will be 20 mhz since before greater channel more noise is filtered and the lower channel is achieved to have less bandwidth, so before the rough in the area opts for that channel, the power of the antenna is described by the distance which as we have seen we will limit it to 1 kilometer to the maximum to be able to have better, more stable coverage; therefore we will be able to place the SSI and WPA/WPA2 password to the signal to be issued so that when configuring the receiving antennas to be able to distinguish the signal and be able to access them safely these steps will be seen in Figure 9.

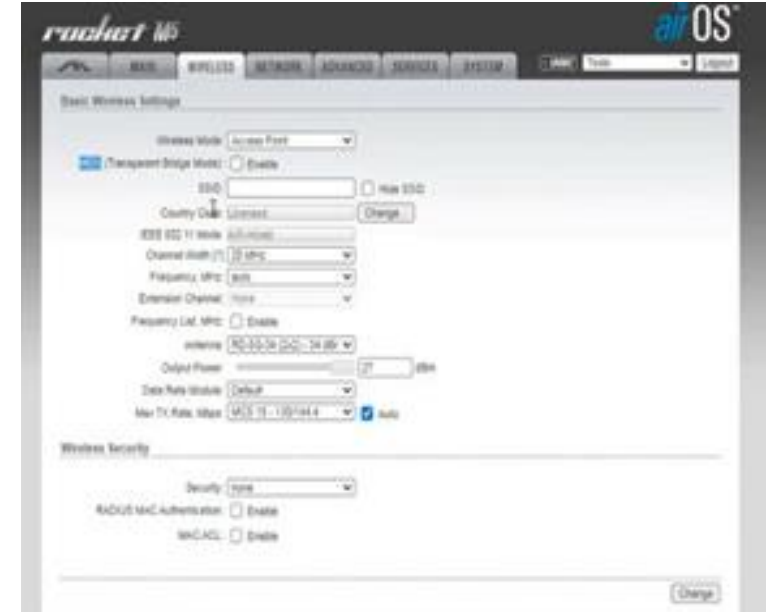

Fig. 11. M5 rocket configuration

For the configuration of the receivers or clients in this WIPS network we must align the LBE-5AC-GEN2 antenna towards the base that would be the sectoral antenna. For the configuration se had to enter a browser and enter this link http://setup.ui.com to enter the configuration software of the antenna to be able to configure its way of use which would be a receiver or base station which would be used as a bridge (bridge) to give a more direct connection to the routers of each house and have a better performance. What would be configured of the antenna is the mode as already mentioned where we ara a scanner of the signals that are detected and therefore selected according to the name that has been placed of the signal of the sector, once located the signal would proceed to place the password, the platform of these steps can be seen in figures 10; to finish the next step is to be able to give limits to the speed whatyou can see in figure 11 .

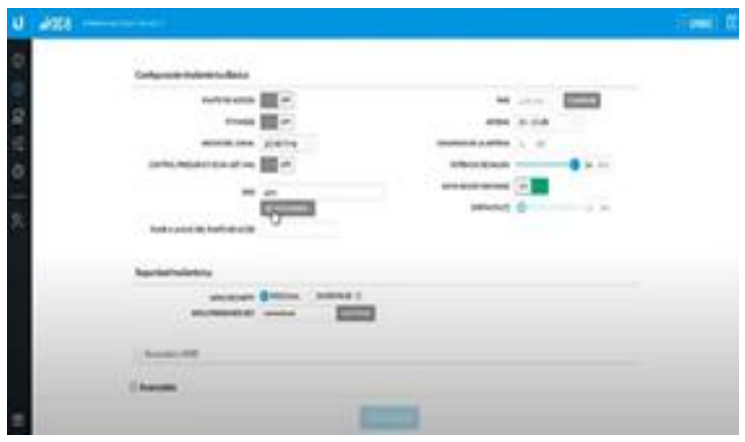

Fig. 12. LBE-5AC-GEN2 Configuration Platform 


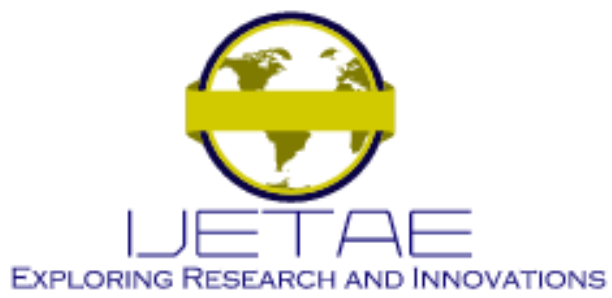

International Journal of Emerging Technology and Advanced Engineering

Website: www.ijetae.com (E-ISSN 2250-2459, Scopus Indexed, ISO 9001:2008 Certified Journal, Volume 12, Issue 01, January 2022)

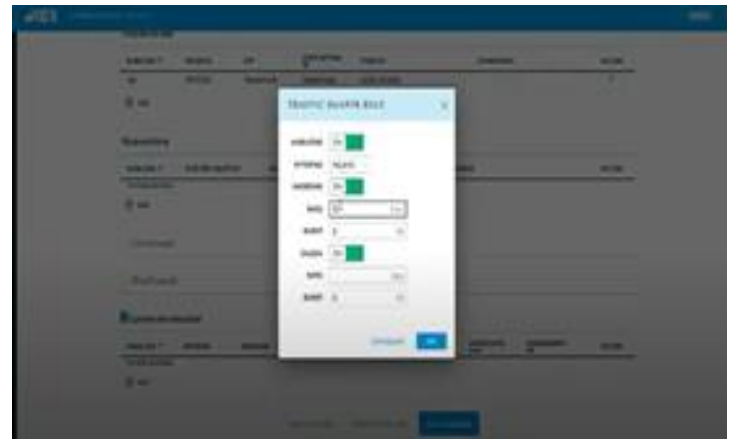

Fig. 13. Speed limit settings

Once the antennas are aligned, we would proceed with the configuration of the routers both the central base and the receiving stations, for which we will start by configuring the main router of the broadcast base that will be connected to the modem and will manage the bandwidth for which the RB750Gr3 router needs a free download software called WinBox that when installing and connecting the roruter by the LAN to the laptop or PC, this software manages to recognize it and allows to access the equipment for its configuration which will begin entering the network area where there will be the option of being able to change the IP, which isplowed by 192.168.20.1 to consequently a DNS should be placed that there is no problem if it is the google 8.8.8.8 as preferred and have an alternative one would be the 8.8.4.4 that is seen in Figure 13. For the following, the ports will be defined as many WAN as LAN Figure 14. The restrictions that will be given will be in the blocks which are in two ways both placing keywords or the way in which pages are blocked directly by placing the links this will help us to be able to limit pages of high data consumption, in the following configuration the bandwidth will be made which indicate a maximum and minimum that we must distribute according to current and future users with respect to the width of band that you have; this can be done for each computer or for the network in general, this would be the most relevant and important.

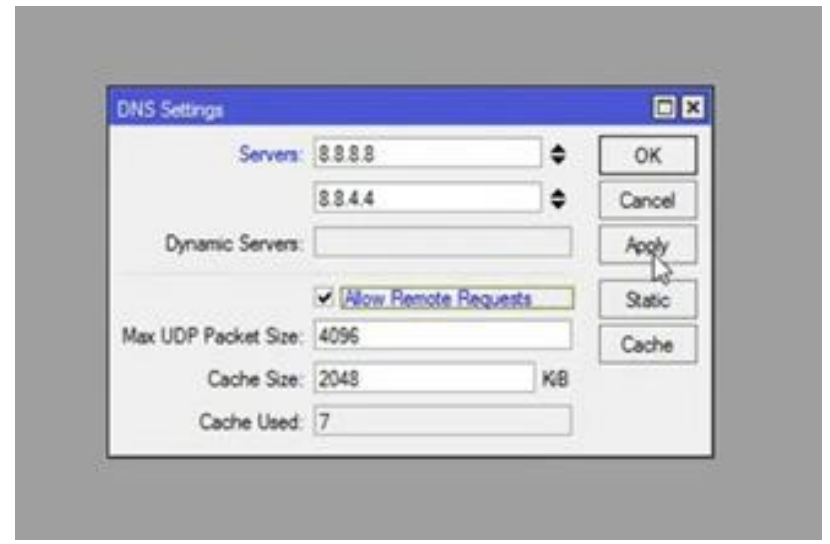

Fig. 14. DNS Configuration

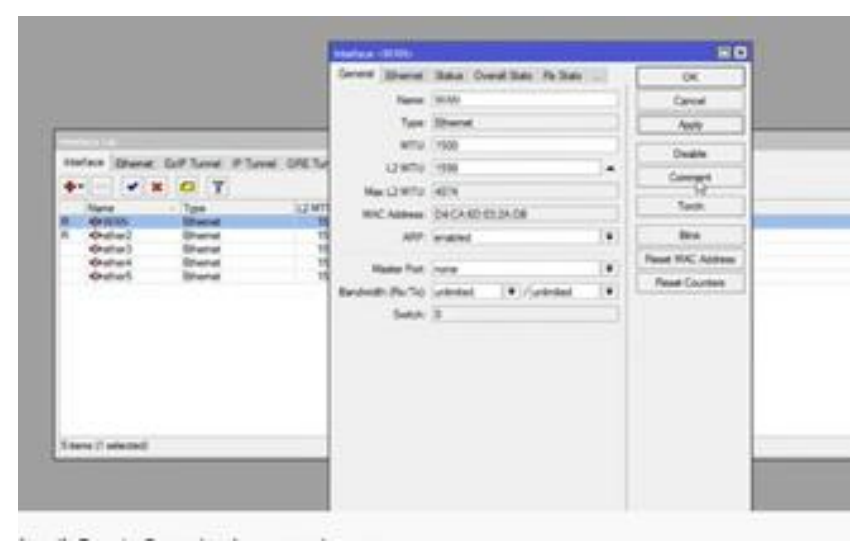

Fig. 15. Configuring LAN AND WAN ports

The second configuration of routers would be to the clients which can be configured andntrando to a browser with the IP 192.168.0.1 once placed will open the portal where by default they have as SSI and PASWOR; admin, admin respectively, once entered the LAN area will put the IPs to work that would be 192.168.10.50 which will now serve as the IP of entry to the configuration, for the following in the wireless option the name of the wifi that will be in the house and the password will be placed and finally in the advanced options it must be put in factory configuration it is placed to record so that this configuration is now the new factory configuration and before a possible reset this equipment maintains the changes. 


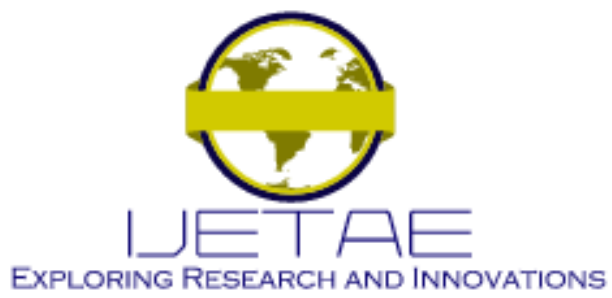

International Journal of Emerging Technology and Advanced Engineering

Website: www.ijetae.com (E-ISSN 2250-2459, Scopus Indexed, ISO 9001:2008 Certified Journal, Volume 12, Issue 01, January 2022)

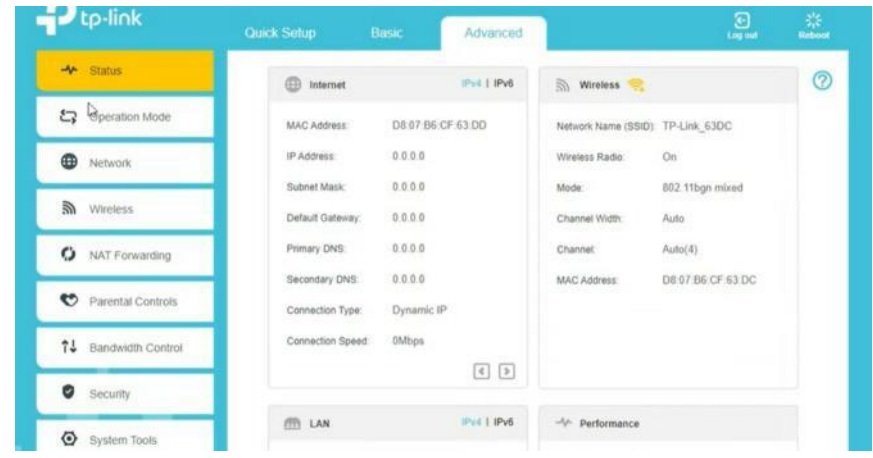

Fig. 16. TL-WR850N Configuration Platform

\section{RESULTS}

In the results of the radio link project there was a good connection at medium distance with the power of the antenna AM-5G19-120, since at the maximum distance and at the closest distance of connection,the signal had low both by the distance or the short distance that the power made it not have the expected performance but nevertheless to that the connection is stable, the approximate area that the equipment would cover will be colored in the following image where the maximum aria is passing the 150 meters to the 520 meters forward. The purple color will indicate that there is no signal, more than the light blue color indicates the coverage areas.

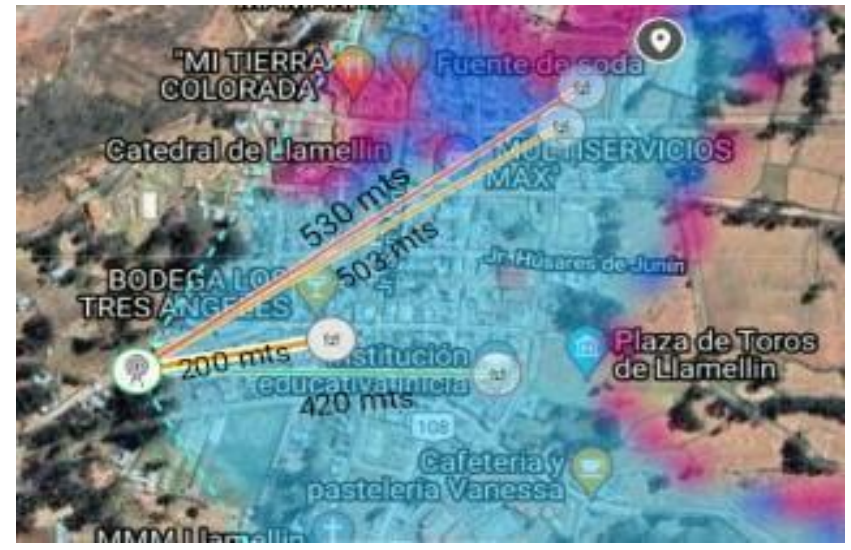

Fig. 17. Coverage area.

From figure 16 we can also see that in the connections the green ones that are at $420 \mathrm{Mts}$ is a good sign since the connection is green; more than in the $200 \mathrm{Mts}$ and $503 \mathrm{Mts}$ is regular so an orange tone, but in the $530 \mathrm{Mts}$ it is indicated that the connection would be null would have no signal.
The fall of the wireless connection occurs only in some cases and peak hours for which it was decided to be able to give it at a certain time, connection to specific equipment to be able to give it solution since, the traffic was heavier in the hours of virtual classes, which is on average from 8 am to noon; very apart before any signal outage the equipment does not delay in reconnecting maximum in $10 \mathrm{~min}$.

The ups and downs of the signal are consistent with what is established in the configuration that has been given and depending on the distance the signal tends to improve or fall in some respects as in the following images shown.

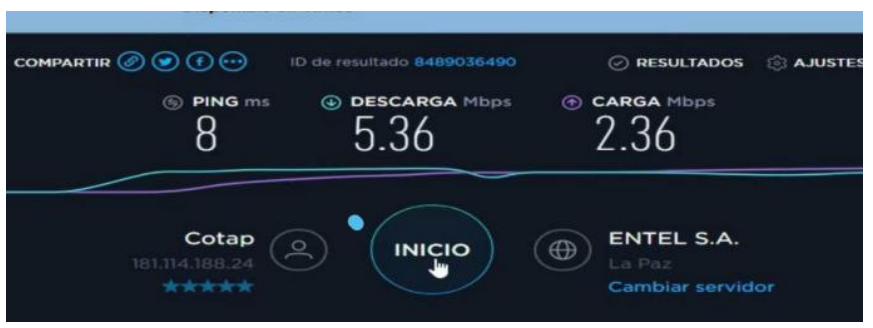

Fig. 18. Signal quality testing at 420 meters.

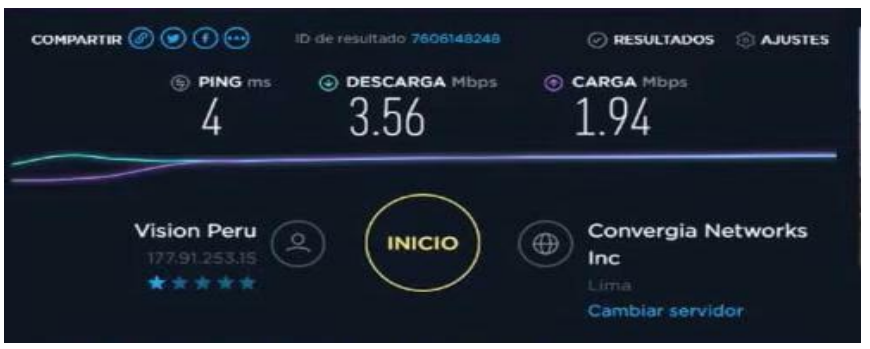

Fig. 19. Figure 18. Signal quality testing at 200 meters.

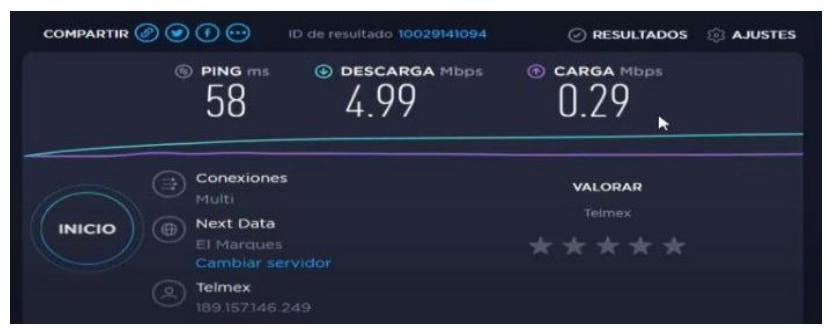

Fig. 20. Figure 19. Signal quality testing at 503 meters 


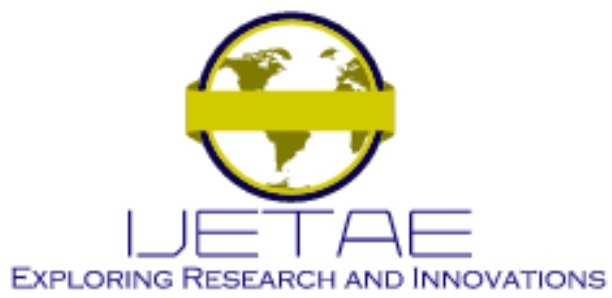

International Journal of Emerging Technology and Advanced Engineering Website: www.ijetae.com (E-ISSN 2250-2459, Scopus Indexed, ISO 9001:2008 Certified Journal, Volume 12, Issue 01, January 2022)

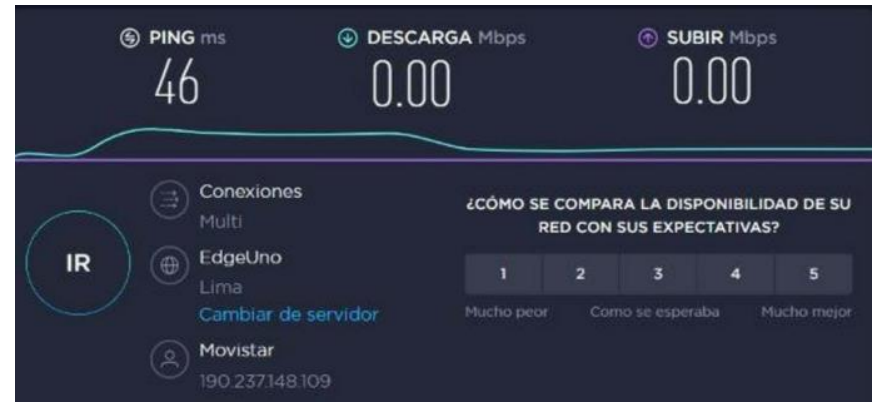

Fig. 21. Figure 20. Signal quality testing at 530 meters

To be able to see the quality of the speeds according to the distance of each antenna we see that the connections do not deliver the estimated according to the configurations by the issue of factors such as difference and signal revote; so, in the following table a comparison of the results obtained will be made seeing that such works the connections

TABLE 6:

RESUlTS OF THE CONNECTIONS

\begin{tabular}{|c|c|c|c|c|}
\hline Clients & $\begin{array}{c}\text { Velocity } \\
\text { Download }\end{array}$ & $\begin{array}{c}\text { Loading } \\
\text { Speed }\end{array}$ & $\begin{array}{c}\text { Distance } \\
\text { from the } \\
\text { base }\end{array}$ & $\begin{array}{c}\text { Cutting } \\
\text { time }\end{array}$ \\
\hline 1 & $\begin{array}{c}5.36 \\
\mathrm{Mbps}\end{array}$ & $\begin{array}{c}2.36 \\
\mathrm{Mbps}\end{array}$ & $420 \mathrm{Mts}$ & $20 \mathrm{~min}$ \\
\hline 2 & $\begin{array}{c}3.56 \\
\mathrm{Mbps}\end{array}$ & $\begin{array}{c}1.94 \\
\mathrm{Mbps}\end{array}$ & $200 \mathrm{Mts}$ & $12 \mathrm{~min}$ \\
\hline 3 & $\begin{array}{c}4.99 \\
\mathrm{Mbps}\end{array}$ & $\begin{array}{c}0.29 \\
\mathrm{Mbps}\end{array}$ & $503 \mathrm{Mts}$ & $15 \mathrm{~min}$ \\
\hline 4 & 0.00 & 0.00 & $530 \mathrm{Mts}$ & 24 \\
& $\mathrm{Mbps}$ & $\mathrm{Mbps}$ & & hours \\
\hline
\end{tabular}

By the table can indicate that the best connection comes from client 1 to exceed what is expected even that the error range of the test must be considered, but the result is very good, and in the other two points 2 and 3 that are in the limits of connection both by the proximity or the great distance we see that there are falls in the quality of signal both in rise and in descent this it shouldbe, that an antenna being so close to the signal revote and the power of it hinders the same connection, and for the other case it would be that the signal is very distant and would arrive weak and would not meet its performance that is why the cut-off time in the two cases of decay of the signal quality also have problems to be able to connect. In client 4 as seen the antenna is in the purple area where the lack of coverage was indicated this would give that there is no connection as seen in the box and in figure 20 .
But despite all the result is very good because before a null connection now if they have a connection that even if it is not what one would like in each connection is enough to improve their education tools.

This implemented system gives better tools to the students of the population, in the face of this pandemic since it manages to give them the access they do not have of the internet, which is known to be a great tool for education; and much more in this pandemic where they will be able to have access to virtual classes, which allows them not to delay in their studies and academic growth that is the most fundamental. Another benefit is to be able to open borders so that the town is more informed to what is happening not only in the area but in the country and outside it and to be able to have communication with distant relatives through video calls and meet that need to see them that due to the pandemic and distance is not possible.

\section{DISCUSSIONS}

In the results we can see that our distance ranges of the radio links give options to different types of links since in research at a maximum distance in average of half a kilometer we work with Point -Multipoint and in [2] in this work a Radius Link of Point-Point is given at a distance of $26 \mathrm{~km}$ so from the results we see that the data sent have a better reception at the point Point-Point but in the present research work it has an advantage that is that if a transmission is cut only that link and the others will remain stable and for this reason also the reception is better in the Point-Point. The similarities that are had in these two radio link investigations that the two achieved a gain of less than $-60 \mathrm{dBm}$; in this research I reach gains around -54 $\mathrm{dBm}$ and $-58 \mathrm{dBm}$ and in [2] the gain of $-52 \mathrm{dBm}$ was achieved so the signals are optimal for the link.

For the system that has been achieved, by making radio links to homes, we have customers at fixed points and they are not movable; quite the opposite en [8] where the wireless links to have as receivers to the tables and laptop of both students and teachers, this is because although the connections that are sought in the two investigations are wireless, they have different clients because one goes to final equipment and the system presented in this research goes to a client base station that will be in charge of receiving through a router to be able to give it just the connection to the final equipment since the distance that is handled influences the system to be used. 


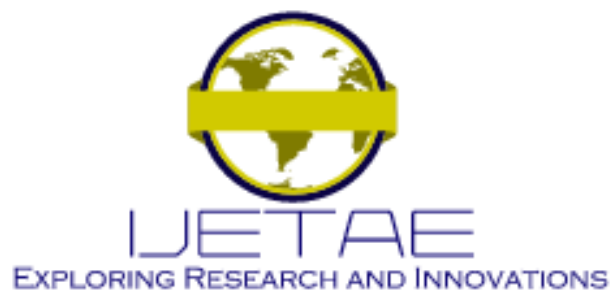

International Journal of Emerging Technology and Advanced Engineering Website: www.ijetae.com (E-ISSN 2250-2459, Scopus Indexed, ISO 9001:2008 Certified Journal, Volume 12, Issue 01, January 2022)

For the configurations through the router of the Mikrotik brand both in this system and in [8] the router RB951Ui$2 \mathrm{HnD}$ allows us to be able to make limitations to be able to restrict both the speeds to be used; the differences are given in that for the research with which we are having the discussion is a model that allows to make captive ports this makes it more expensive but, in this research and system those configuration specifications were not needed, so we opted for a more economical equipment such as the RB75Gr3.

In the system created in our results we have managed to have up to a distance uploads and downloads at a speed that was expected, as well as in [7] the speed reached 4 Mbps of download and 1.7 Mbps of upload, that would be the average something that in our system was given 5.36 Mbps in downloads and 2.36 Mbps in upload and this difference and better signal is due to the fact that in [7] there is more client between about 50 compared to the system that has been presented in the research of maximum of 15 customers and having less can better direct the internet signal and be able to give a better quality, since the greater the number of customers it is more complicated to be able to redistribute the signal better.

\section{CONCLUSIONS}

It is concluded that in the radio-link with the sectoral antenna the best signal we have at a medium distance since while they are put in the limits of the signal; this causes ittofall so the distance of $420 \mathrm{Mts}$ is a distance that manages to get better out of the radio link.

It is concluded that in the cut or saturation that occurs in the radio-links, but the cut compared to the other signals is better since it arrives in a very short time that is manageable for reconnection automatically, either by changing the channel or by saturation of the signal.

It is concluded that it can be established that this system allows children to have a great tool to be able to continue with their virtual classes by having this tool that is access to the internet, and as an extra benefit to be able to communicate with distant relatives, which due to this pandemic is not possible; but with video calls you can.

For future work on this system, it should be possible to improve the central base of the radio link with more sectoral frontsin order to increase the coverage aria with a better signal; and to be able to see results in other types of remote villages.
The limitations that have been had in the radio link is not being able to be totally in the field for work reasons; another limitation that was had is to be able to convince the owner of the house where the base was set up since they still had some distrust; although it was possible to install the base had to be given incentive so that it can be given.

\section{REFERENCES}

[1] IBRD - IDA, "People who use the Internet (\% of population) | Data," 2019.

https://datos.bancomundial.org/indicator/IT.NET.USER.ZS?end=20 $19 \&$ most_recent_value_desc $=$ false \&start $=1960 \&$ type $=$ shaded \&view $=$ chart\&year=201 (accessed Sep. 14, 2021).

[2] B. Díaz-Chang and D. D. Ayala Hernandez, "High-speed network that allows internet access coverage in rural parishes in Latin America," J. Bus. Entrep. Stud. JBES, ISSN-e 2576-0971, Vol. 4, No.1 (January - June), 2020,vol. 4, no. 1, pp. 1-18, Jun. 2020, Accessed: Sep. 14, 2021. [Online]. Available: https://dialnet.unirioja.es/servlet/articulo?codigo $=7472734$.

[3] National Institute of Statistics and Informatics, "Net Rate of Attendance at Primary Education of the Population from 6 to 11 Years of Age, According to Geographic Scope, 2008 - 2019," INEI,2020. https://www.inei.gob.pe/estadisticas/indicetematico/sociales/ (accessed Sep. 14, 2021).

[4] National Institute of Statistics and Informatics, "Net Rate of Attendance at Initial Education from 3 to 5 Years of Age, According to Geographic Scope 2008 - 2019." https://www.inei.gob.pe/estadisticas/indice-tematico/sociales/ (accessed Dec. 07, 2021).

[5] National Institute of Statistics and Informatics, "Households that access internet service, by years, according to geographical areas." https://www.inei.gob.pe/estadisticas/indice-tematico/tecnologias-dela-informacion-y-telecomunicaciones/ (accessed Nov. 22, 2021).

[6] National Institute of Statistics and Informatics, "Households that have at least one computer, for years, according to geographical areas." https://www.inei.gob.pe/estadisticas/indicetematico/tecnologias-de-la-informacion-y-telecomunicaciones/ (accessed Nov. 22, 2021).

[7] A. Vila Gamarra, "Deployment of a wireless network based on the PPDIOO methodology for the improvement of internet service in the urbanization of Palián," National University of Central Peru, Huancayo - Peru, 2020.

[8] E. A. Yoza Segovia, "Implementation of a Wireless Network for Internet Access with Ubiquiti Technology in the Ocho de Enero Educational Unit," Jul. 2020, Accessed: Nov. 22, 2021. [Online]. Available: http://repositorio.unesum.edu.ec/handle/53000/2265.

[9] C. J. Cáceres Malpica, "Implementation of a wireless network to provide internet to schools $\mathrm{N}^{\circ} 31487$ and José Gálvez de Perene, Chanchamayo - 2021," Universidad Nacional del Centro del Perú, 2021.

[10] V. Di Rienzo, G. Pica, and E. Roche, Implementation of a network for the royal tech company. 2008 


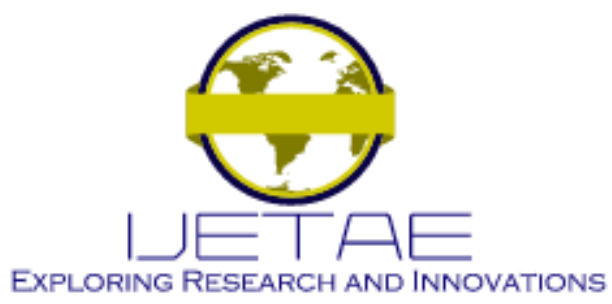

International Journal of Emerging Technology and Advanced Engineering

Website: www.ijetae.com (E-ISSN 2250-2459, Scopus Indexed, ISO 9001:2008 Certified Journal, Volume 12, Issue 01, January 2022)

[11] Ubiquiti, "LBE-5AC-Gen2 Quick Start Guide." https://dl.ubnt.com/qsg/LBE-5AC-Gen2/LBE-5AC-Gen2_ES.html (accessed Dec. 07, 2021).

[12] Ubiquiti, "AM-5G19-120 Quick Start Guide." https://dl.ubnt.com/qsg/AM-5G19-120/AM-5G19-120_ES.html (accessed Dec. 07, 2021).

[13] Ubiquiti, "Powerful 2x2 MIMO airMAX® BaseStation."
[14] MikroTik, "MikroTik Routers and Wireless - Products: hEX." https://mikrotik.com/product/RB750Gr3 (accessed Dec. 07, 2021).

[15] Tp-ink, "TL-WR850N | 300Mbps Wireless N Router | TP-Link Iberia." https://www.tp-link.com/es/service-provider/wifi-router/tlwr850n/ (accessed Dec. 07, 2021). 